\title{
nahR, encoding a LysR-type transcriptional regulator, is highly conserved among naphthalene-degrading bacteria isolated from a coal tar waste-contaminated site and in extracted community DNA
}

\author{
Woojun Park, ${ }^{1}$ Parasuraman Padmanabhan, ${ }^{1} \dagger$ \\ Saraswathi Padmanabhan, ${ }^{1}$ Gerben J. Zylstra ${ }^{2}$ \\ and Eugene L. Madsen ${ }^{1}$
}

1 Department of Microbiology, Cornell University, Ithaca, NY, 14853-8101, USA

2 Biotechnology Center For Agriculture and the Environment, Cook College, Rutgers University, New Brunswick, NJ, 08901-8520, USA
Author for correspondence: Eugene L. Madsen. Tel: +1 607255 3086. Fax: +1 6072553904. e-mail: elm3@cornell.edu

In Pseudomonas putida strain G7, a LysR-type positive transcriptional activator protein encoded by nahR is necessary for activation of two operons involved in naphthalene catabolism [Schell, M. A. \& Poser, E. F. (1989). J Bacteriol 171, 837-846]. The role of an nahR homologue, NCIB-nahR, in another naphthalenemetabolizing bacterium, $P$. putida NCIB 9816-4 was verified. Targeted disruption of NCIB-nahR by homologous recombination resulted in a growth defect in the presence of naphthalene or salicylate as sole carbon and energy source. The nahR homologues and intergenic regions between nahR-like and nahG-like genes from $P$. putida NCIB 9816-4 and seven bacteria native to a naphthalene-rich coal tar contaminated site were amplified by PCR using degenerate primers. The amplified nahR homologues and the intergenic regions were cloned and sequenced. Alignment of the deduced amino acid sequences from NahR homologues revealed that NahR-like proteins showed only minor variations in all investigated naphthalene-degrading isolates. The intergenic regions, together with known NahR-binding sites showed the consensus NahR-protein-binding sites (5'-ATTCACGCTN ${ }_{2}$ TGAT-3'). Surprisingly, amplified intergenic regions from naphthalene-degrading micro-organisms native to this study site were $100 \%$ identical to that of the pDTG1 plasmid (an archetypal naphthalene-catabolic plasmid from Pseudomonas putida NCIB 9816-4), but the nahR coding regions were not. DNA representing the uncultured microbial community was extracted from six sediment samples with varying coal tar exposure histories. PCR amplification of nahR from sediment DNA was observed in contaminated samples, but in uncontaminated samples only following laboratory incubation with naphthalene. The sedimentderived PCR products were sequenced and also found to be almost identical to known nahR genes. Thus, the structure and function of nahR-nahG regulatory genes appear to be highly conserved.

Keywords: microbial community, sediment, biodegradation, diversity, nahG, salA

\section{INTRODUCTION}

Knowledge of the regulation of pollutant-degrading pathways may facilitate metabolic adaptation processes, hence the use of micro-organisms in environmental clean-up efforts (Pieper \& Reineke, 2000; Timmis \&

† Present address: National Environmental Engineering Research Institute (NEERI), Nehru Marg, Nagpur - 440 020, India.

The GenBank accession number for the sequences of the tnpA-like gene, nahG and nahR of $P$. putida NCIB 9816-4 is AF491307. The GenBank accession numbers for the sequences of the nahR-nahG intergenic region and the nahR homologue genes of strains Cg1, Cg2, Cg5, Cg7, Cg9, Cg11, Hg8 and N1 are AF491308-AF491315, respectively. The GenBank accession numbers for the sequences of nahR from sediment-extracted DNA are AF491316-AF491324. 
Pieper, 1999). Naphthalene is the simplest member of a widespread, well-studied class of environmental pollutants, polycyclic aromatic hydrocarbons (PAHs; Shuttleworth \& Cerniglia, 1995; Sutherland et al., 1995). The NAH7 naphthalene-catabolic plasmid in Pseudomonas putida G7 has been well characterized (Connors \& Barnsley, 1980; Eaton, 1994; Schell, 1985; Serdar \& Gibson, 1989; Yen \& Gunsalus, 1982). Analysis of transposon Tn5-induced mutants of the NAH7 plasmid (Schell, 1985; Schell \& Wender, 1986) showed that nab operons are divided into two clusters. The first (upper operon) has genes encoding enzymes that convert naphthalene to salicylate and the second (lower operon) includes genes for the oxidation of salicylate to acetyl coenzyme A and pyruvate (Zhou et al., 2002). The $\mathrm{Nah}^{-}$ $\mathrm{Sal}^{-}$phenotype was obtained when a Tn5 insertion mutation immediately upstream from the first gene of the lower operon, $n a h G$, occurred in the NAH7 plasmid (Schell, 1985). This defined the regulatory region containing the gene encoding the NahR protein.

The NahR protein, a LysR-type transcriptional regulator (LTTR), is necessary for activation of both the upper (genes nahA-F) and lower (genes nabG-M) operons on the NAH7 plasmid (Huang \& Schell, 1991; Schell, 1985, 1986, 1993; Schell et al., 1990; Schell \& Poser, 1989; Schell \& Wender, 1986). Studies of the NAH7 plasmid in P. putida G7 have shown that NahR is constitutively expressed at low levels (Cebolla et al., 1997). When bound to its inducer, salicylate, NahR activates both nah operons by interacting with DNA enhancer sequences upstream of the promoter region in upper and lower nah operons (Schell \& Poser, 1989). The $5^{\prime}$ flanking region of known nabR genes is the divergently transcribed nahG-nahR promoter region. NahR binding in this $-60 \mathrm{bp}$ region upstream of the $n a b G$ gene transcription start site induces $n a b G$ gene transcription, but represses its own expression by negative autoregulation (Schell \& Poser, 1989; Schell \& Wender, 1986; Yen \& Serdar, 1988). The exact mechanism of autoregulation remains to be elucidated (Yen \& Serdar, 1988).

P. putida NCIB 9816 is another well-characterized bacterium capable of utilizing naphthalene as sole carbon and energy source (Cane \& Williams, 1986; Kurkela et al., 1988; Serdar \& Gibson, 1989; Simon et al., 1993). This trait is conferred in P. putida NCIB $9816-4$ by an $81 \mathrm{~kb}$ plasmid, pDTG1, that encodes key early enzymic steps in naphthalene degradation (Connors \& Barnsley, 1980; Kurkela et al., 1988; Serdar \& Gibson, 1989; Simon et al., 1993) The structural genes encoding naphthalene-degrading pathways in a variety of bacteria are highly conserved (Bosch et al., 1999, 2000; Goyal \& Zylstra, 1996; Serdar \& Gibson, 1989; Yen \& Serdar, 1988), although distinctive nahAcAd homologues ( $p h n, n a r)$ have been described (Fuenmayor et al., 1998; Goyal \& Zylstra, 1997; Larkin et al., 1999; Laurie \& Lloyd-Jones, 1999, 2000; Saito et al., 2000). The diversity and function of the regulatory region for naphthalene-catabolic operons is poorly explored. As of December 2001, GenBank listed nahR homologues from P. putida G7, P. stutzeri AN10 and Ralstonia sp. strain U2. Reports about nabR from environmental nucleic acid extracts are restricted to a single study (Silva et al., 1995) which reported ethidium bromide- and hybridization-based detection of NahR amplified by PCR from four soil samples: amplification was sporadic and no sequence analysis was performed. Stuart-Keil et al. (1998) showed by using Southern blot hybridization and RFLP analysis that plasmids carried by bacteria native to a coal-tar-contaminated site are closely related to pDTG1. With the above-described genetic information as a foundation, we investigated the degree to which the genetic regulatory system in the NAH7 plasmid applies to micro-organisms native to naphthalene-contaminated sediments and groundwater in South Glens Falls, NY, USA

\section{METHODS}

Bacterial strains, plasmids and growth conditions. Bacterial isolates (Cg1, Pseudomonas putida Cg1; Cg2, Pseudomonas fluorescens $\mathrm{Cg} 2 ; \mathrm{Cg} 5$, P. fluorescens $\mathrm{Cg} 5 ; \mathrm{Cg} 7$, Pseudomonas strain Cg 7; Cg9, P. fluorescens Cg9; Cg11, Pseudomonas mendocina $\mathrm{Cg} 11$; N1, P. fluorescens $\mathrm{N} 1$; and $\mathrm{Hg} 8$, Burkholderia gladioli $\mathrm{Hg} 8$ ) and their plasmids from the coal-tarcontaminated site have been described (Herrick, 1995; Herrick et al., 1997; Hohnstock et al., 2000; Stuart-Keil et al., 1998). These and other bacterial strains, vectors and plasmids used in this study are listed in Table 1 . Naphthalene-degrading bacteria, and plasmid-cured and other strains derived therefrom were grown at $22{ }^{\circ} \mathrm{C}$ (room temperature) and maintained on mineral salts basal medium (MSB; Stanier, 1966) with either naphthalene (vapour or a suspension of crystals; MSB$\mathrm{N})$ or glucose (MSB-G) as sole carbon source. Other culture media were prepared according to the procedures described by Herrick et al. (1997) and Hohnstock et al. (2000). All Escherichia coli strains were grown with shaking (60 r.p.m.) at $37^{\circ} \mathrm{C}$ in Luria-Bertani (LB) medium. When required, the appropriate antibiotics and reagents were added to the medium: X-Gal $\left(60 \mu \mathrm{g} \mathrm{ml}^{-1}\right)$, kanamycin $\left(100 \mu \mathrm{g} \mathrm{ml}^{-1}\right.$ for $E$. coli strains, $50 \mu \mathrm{g} \mathrm{m}^{-1}$ for Pseudomonas strains), ampicillin $\left(50 \mu \mathrm{g} \mathrm{ml}^{-1}\right)$, glucose $(10 \mathrm{mM})$, salicylate $(2.5 \mathrm{mM})$. Growth was monitored by measuring the $\mathrm{OD}_{600}$ of the cultures with Spectronic 21 (Spectronic Instruments).

PCR amplification of nahR and nahR-nahG intergenic region. Plasmid isolation, gel electrophoresis, transformation and amplification of DNA by PCR were performed by standard procedures (Ausubel et al., 1994; Miller, 1972; Sambrook et al., 1989). The conserved regions of G7-nabR (P. putida G7), $n a b R(S)$ (P. stutzeri AN10) and NCIB-nabR (P. putida NCIB 9816-4) (GenBank accession no.s M22723, AF039534 and AF491307, respectively) were used to design the degenerate primers of PCR for amplifying nabR-like genes. The conserved regions of G7-nahG (P. putida G7), nahG(S) (P. stutzeri AN10) and NCIB-nabG (P. putida NCIB 9816-4) (GenBank accession nos M60055, AF039534 and AF491307, respectively) together with the conserved nabR genes were used to design the degenerate primers for amplifying the intergenic region between nabG and nabR genes. The position of each primer is illustrated in Fig. 1(a). Primers used in this study were as follows (nomenclature: o, outer; i, inner; F, forward; R, reverse; pro, promoter; msc, multiple cloning site; restriction enzyme sites, for future cloning purposes, are underlined): onahR-F, 5'-CGCGAATTCATGGAACTGCRTGAYCTGGA-3' (29 bp); onahR-R, 5'-CGCGAATTCTCA- 
Table 1. Bacterial strains and plasmids used in this study

\begin{tabular}{|c|c|c|}
\hline Strains or plasmid & Description & Reference \\
\hline Pseudomonas putida NCIB 9816-4 & pDTG1 plasmid, naphthalene-degrader & Simon et al. (1993) \\
\hline $\begin{array}{l}\text { Pseudomonas Cg1, Cg2, Cg5, Cg7, } \\
\text { Cg9,Cg11, N1, G7, Burkholderia } \\
\text { gladioli Hg8 }\end{array}$ & Naphthalene-degraders & $\begin{array}{l}\text { Herrick et al. (1997); Stuart- } \\
\text { Keil et al. (1998) }\end{array}$ \\
\hline $\begin{array}{l}\text { Pseudomonas Cg1CR, Cg2CR, } \\
\text { Cg5CR, Cg7CR, Cg9CR, G7CR, } \\
\text { NCIB 9816-4CR }\end{array}$ & Plasmid-cured derivatives of naphthalene-degraders & Stuart-Keil et al. (1998) \\
\hline Strain RK1 & Pseudomonas putida NCIB 9816-4 $\Delta$ nahR:: kan lacZ ${ }^{+}$ & This study \\
\hline Escherichia coli SY327 ipir & $\begin{array}{l}\lambda \text { pir } \Delta(\text { lac pro }) \operatorname{argE}(\mathrm{Am}) \text { recA56 nalA } \operatorname{Rif}(\lambda p i r) ; \text { carries } \pi \\
\text { protein for } \mathrm{R} 6 \mathrm{~K} \gamma \text { ori }\end{array}$ & Simon et al. (1983) \\
\hline Escherichia coli S17-1 $\lambda$ pir & $\begin{array}{l}\operatorname{trp} \text { recA thi pro hsdM+ } \mathrm{RP} 4-2-\mathrm{Tc}:: \mathrm{Mu}:: \mathrm{Km} \mathrm{Tn} 7 \text { ipir } \mathrm{Sm}^{\mathrm{r}} \text {; } \\
\text { hsdR mutant }\end{array}$ & Simon et al. (1983) \\
\hline $\mathrm{INV}-\alpha \mathrm{F}^{\prime}$ & $\begin{array}{l}\text { Cloning host } \mathrm{F}^{\prime} \text { end } A 1 \text { recA1 hsdR17 }\left(\mathrm{r}_{\mathrm{K}}^{-} \mathrm{m}_{\mathrm{K}}^{+}\right) \text {supE44 thi-1 } \\
\text { gyrA96 relA1 } \phi 80 \operatorname{lac} Z \Delta M 15 \Delta\left(\operatorname{lacZYA} \text {-argF) U169 } \lambda^{-}\right.\end{array}$ & Invitrogen \\
\hline pVIK112 & $\mathrm{Km}^{\mathrm{R}}$, R6Kori $\mathrm{V}$, suicide vector & Kalogeraki \& Winans (1997) \\
\hline pWJ100 & $\mathrm{Km}^{\mathrm{R}}$, internal nabR fragment (derived from pVIK112) & This study \\
\hline pCR2.1-TOPO & $\mathrm{Km}^{\mathrm{R}} \mathrm{Ap}^{\mathrm{R}}$, Cloning vector & Invitrogen \\
\hline
\end{tabular}

ATCMGWAAACAGSTCRAAC-3' (31 bp); inahR-F, 5'CGCGAATTCGTRTTCAACSAGYTGMTGGTCKR C-3' (33 bp); inah-R, 5'-CGCGAATTCGAARGTACGCTCGCTGGTYA-3' (29 bp); pro-F, 5'-CGCGAATTCGGTCAGGCCCAGGTTCTC-3' (27 bp); pro-R, 5'-CGCGGATCCASCGAYGCGCAAGSCWRGTTTMTT-3' (33 bp); msc-R, 5'-ACCATGGTCATAGCTGTTTCCTG-3' (23 bp). The following steps were taken for each PCR reaction. A $10 \mu \mathrm{l}$ volume of sterile water was added to each PCR tube and bacterial cells were transferred to the PCR tube with a sterile platinum needle from a freshly grown colony. The cells were lysed by heating to $95^{\circ} \mathrm{C}$ for $5 \mathrm{~min}$. PCR amplification was carried out using a PTC-200 thermocycler (MJ Research). The $50 \mu \mathrm{l}$ volume reaction mixture in each tube contained each primer $(0.5 \mu \mathrm{M}), 1^{\circ} \mathrm{C}$ PCR buffer (Gibco-BRL), dNTPs $(0.2 \mathrm{mM})$, $\mathrm{MgCl}_{2}(1.5 \mathrm{mM})$ and $1.25 \mathrm{U}$ Taq DNA polymerase (GibcoBRL). A cycling regime of $94^{\circ} \mathrm{C}$ for $5 \mathrm{~min}(1$ cycle $), 94^{\circ} \mathrm{C}$ for $1 \mathrm{~min}, 60^{\circ} \mathrm{C}$ for $1 \mathrm{~min}, 72{ }^{\circ} \mathrm{C}$ for $1 \mathrm{~min}(35$ cycles $)$ and $72{ }^{\circ} \mathrm{C}$ for $5 \mathrm{~min}$ ( 1 cycle) was employed. Amplicons were separated by electrophoresis in $2 \%$ agarose gel.

Insertional inactivation by homologous recombination. Suicide transcriptional fusion vector, pVIK112 (containing stop codons immediately downstream of EcoRI cloning sites, a kanamycin marker and the R6KoriV region so that it cannot replicate without the $\lambda$ pir replication system; maintained in $E$. coli SY327 ipir] (Kalogeraki \& Winans, 1997; Simon et al., 1983), was used for Campbell-type homologous recombination with pDTG1 (Fig. 1b). The amplified 278 bp fragment (37-297 bp region plus EcoRI cohesive ends) of the internal NCIB-nahR gene fragment was amplified using the inahR$\mathrm{F} /$ inahR-R primer pair and subcloned into the EcoRI cloning site of pVIK112, creating $\mathrm{pWJ100.}$. Clone characterization was performed by using the inahR-F/mcs-R primer pair (Fig. 1b) which amplified a $271 \mathrm{bp}$ fragment (data not shown). pWJ100 was introduced by electroporation into E. coli S17-1 ipir that has the tra region of RP4 (Simon et al., 1983). Then, conjugation was performed by filter-mating with E. coli S171 ipir (pWJ100) and P. putida NCIB 9816-4 as donor and recipient, respectively. The transconjugants (strain RK1; $P$. putida NCIB 9816-4 SnahR) were selected on MSB-P medium (MSB plus $0 \cdot 1 \%$ pyruvate) containing kanamycin at room temperature $\left(22^{\circ} \mathrm{C}\right)$.

Sediment samples from the contaminated study site. Sediment samples were obtained in South Glens Fall, NY (Herrick, 1995; Herrick et al., 1997; Hohnstock et al., 2000). Sediments representing a broad spectrum of locations and contaminant exposure histories were examined. Unless otherwise specified, all samples were transported from the site to the laboratory and stored at $4{ }^{\circ} \mathrm{C}$ until used. 'Uncontaminated aquifer' and 'contaminated aquifer' samples were obtained via aseptic coring techniques from near the site water table (Madsen et al., 1991) in 1989 and were stored in core barrels. The 'contaminated source' sample, very rich $\left(>30 \mathrm{mg} \mathrm{kg}^{-1}\right)$ in coal tar and naphthalene, was excavated from the site in 1991 and placed in a bucket; similarly 'clean sediment' was excavated in 1991, but from outside the contaminated zone. 'Seep sediment' was gathered in 1995, $400 \mathrm{~m}$ down gradient from the contamination source in a low elevation area where naphthalene $\left(\approx 10 \mathrm{mg} \mathrm{kg}^{-1}\right.$ ) had accumulated in an organic matter-rich stream bed. 'On site frozen seep' was gathered from the seep area in 1993, but immediately frozen in liquid nitrogen and stored at $-20^{\circ} \mathrm{C}$ after reaching the laboratory. Sediments were incubated three ways. In one pair of treatments, $2 \mathrm{~g}$ sediment samples were amended with $50 \mathrm{mg}$ naphthalene crystals and distilled water $(100 \mu \mathrm{l})$ with and without $\mathrm{NH}_{4} \mathrm{NO}_{3}(2.5 \mathrm{mg})$ plus $\mathrm{K}_{2} \mathrm{HPO}_{4}(2.5 \mathrm{mg})$ and incubated for 2 weeks at room temperature $\left(22^{\circ} \mathrm{C}\right)$. The third treatment replaced the above $\mathrm{NH}_{4} \mathrm{NO}_{3} / \mathrm{K}_{2} \mathrm{HPO}_{4}$ mixture with the full complement of inorganic nutrients $(500 \mu \mathrm{MSB}$ medium; Stanier et al., 1966) and the incubation was at $30^{\circ} \mathrm{C}$ for 2 days.

Sediment DNA extraction and PCR amplification. Nucleic acids from various sediment samples were extracted using a FastDNA spin kit for soil (Qbiogene) according to the manufacturer's instructions. Sediment samples $(0.5 \mathrm{~g}$ dry wt) and $100 \mu$ l elution buffer were used for each DNA extraction. For PCR amplification of the sediment-extracted DNA, it was diluted 1:10 with distilled water. The $50 \mu \mathrm{l}$ PCR reaction 
(a)

AGCGTGGTGGGCACGGCGGCCAACGTGGCCGATGTCACCCAGGTCGATAAGCTGCTGCACGGCGATGAGA ACATGGTCGOTGCCGACGCGGGTTACACCGCCGTCGAGAAACGCCCTGAMCATGMAGGCCGGGAGGTCA CTGGCAGATOECCGCCCECCETAGTACTTACAAGAAGCTTEATAAACECAGTECTTTGTACAAAGCCEC CGCARGATTEAGAAGGCCAAGGCTCAGGTAOGAGCCAAGGTCGAGCATCCGTTCCGGGTGATCAAGCGCC AGTTCOOTTAT GT GAAGGTOCGCTTCCGTOGTCTGOCGAACAACACOOCOCAACTGOTGACOCTGTTCOC GCTGTCGAACT GTGGATGGCGCGCCGACATTTACTGGCGNATGCAGGAGNGGTGOGCCTGTAATGIGGG AART GGCT GOOGCGAGGTGCTCGCGGCGGCTAAAAACACAGAAATAAGCGGGT GATCTGAGCGTTTTTG TCGATTT GCOGCTTTTAAAATCGGCAGGGGCTGAAGT CAGCCAGAAATACACAACTACTTCAGACCATC

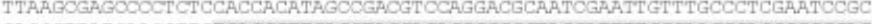
GACCGTTATCAACGTT GTCACCCTTEACGTAGCACACCCCGGCTACCATTTTCCCAAOCCAGGCGCGCAC

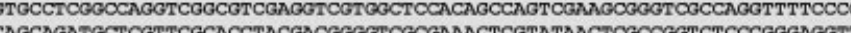
CGCT CATCOMTO le A

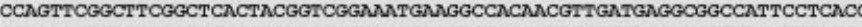
GGAAAAGTGAGGATATGGCCGTCAAGCCCTAGGTACATCTGCGGTACGTCCACCAAGTGCTCGTCGATGC CCTGGGCTCGATAGGCTTCGCGCAGGTGTAGGCTGTCGACCATCCCCCGATAGGCACAGGTGCCGCTGA GCGCGGTACCT GTGGGGCCAGCCCCT GACCTTCCNGCACATGACTACGCAGCGCTGACTT GATTCCGTCE GCACCGATTAGAAGGTCACAGCGGTECTCTGTGCCGTCGGCGAATAGCACTTGCACTTCGCCCCCCTTT: GCTCGACCTGTGTGOCGCOCTTCCTGAATTOGGCGATACCTTTTGGGAGGTGATTTACTAGGGCATCGAO GANATCCGCOCGGT GTACCGAGGACTGGCCCACGCOCGGAGCGATGGTCGCTCCCAMATAGCTGGCATCC CTGCOGCGCOGCCACTCGAACCACACGTCCTCOCAGGGCTCCGAGGTACGGTCGGCGACCTGCAAGTAGG

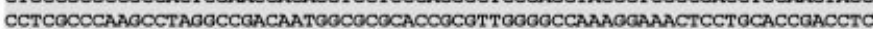
ACCANAAGCOGGCGCGCACTCGAACAGCTGTACTTGGAGATGGGAGTAGCGACAGAGCTCCAGAGCCAAG pro-5

1891 GCAACGCCGGANATCCCGCCGCCGATGATACCGATGCGCANGCCAGGTTTATTGTTTTTCATGCTGGTAC 1961 TCATGATGGTTTTACAGTTGACTGTTAATAAOCATAACGGAGTAAAGAATATTGATAAAGACACCGACCE 2031 CTATACAATATATTATA.BGCGTGAATATTGCTGCCTGCCAGGCGGGACGCOGGCATAACCCGAGGGAGGC OnahR-F

InahR-F

2101 TCCATGGAACTGCGTGATCTGGATTTAAACCTGCTGGTGGTGTTCAACGAGCTGCTGGTCTGCAAACGCO 2171 TCTCTATCGTTGCCGAGAACCTGGGCCTGMCCCAGCCTGCTGTCAGCMATECGCTGNANCGCCTGCGCAC TCTCTATCGTTGCOGAGANCCT

AGCGCTACAGGACCAACTTTTCGTGCOCACCTACCAGGGTATGGAACCCACACCCTACGCCGCGAACTT GCCGAGCCCGTCGCCTTGGCCATGCACGCCCT GCGCGAAGCCCTGCAGCAOCAT GAGCGCTTCEATCCGC TGACCAOCOAOCOTACTTTCACCCTOCCCATGACCOACATCOGCGAOATCTACTTCATGCCOCGGCT

\section{IahR- $\mathrm{R}$}

GATGCGATTACTCTTCAAGCCCCCAATTGCGCGATCAGCACCGT GCGCGACAGTTCGATGAGCCTGAT

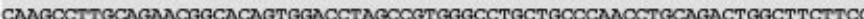
AGCECOEGCNECTCCACAATCACTACGTGTECCTGTGTCGCAAGGACCATOCGGCCACCCGCGAACCCC:

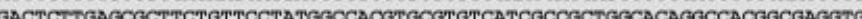

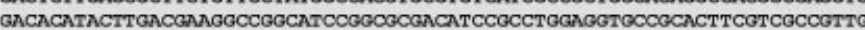
GCCACATACTCCAGCGCACCGAGCTGCTCGOCACT GTGCCEATACGITTCECCGACTGCTGCGTAGAGCD CTTCOOTCTOAOCOTCTTOCCOCACCCAOTOOCCTTOCCOGAAAT COCCATCAACATOTTCTOGCATOC AAATACCACCAGGACCTCGCCAATATCTGOTTGCOGCAACTGATGTTCGACCTOTTTTCTGATTGA:A.A,

3011 A.A.

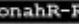

(b)

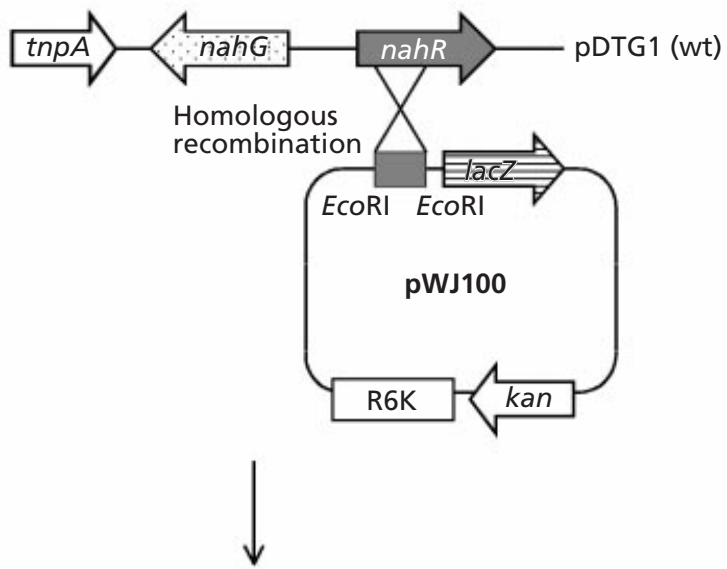

RK1 strain onah R-F

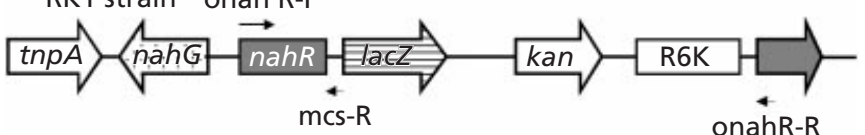

$\frac{1}{2}$

Fig. 1. Genetic locus of this study and diagram of plasmid construct prepared. (a) Sequence of NCIB-nahR from plasmid pDTG1 and positions of PCR primers. The NCIB-nahR gene sequence, putative nahR-nahG promoter region, putative NCIB-nahG gene and flanking tnpA-like (transposase-like) gene in pDTG1 plasmid of $P$. putida NCIB 9816-4 are shown. The degenerate primers from the conserved regions of NCIB-nahR, nahR and nahR(S), and the primers used for cloning the nahG gene promoter region are indicated as arrows above the cognate sequences. (b) Construction of pWJ100 and Campbell-type homologous recombination with pDTG1. The internal region of NCIBnahR is depicted by a grey box. The arrows indicate the direction of transcription. 
mixture contained each primer set (onahR-F/inahR-R or onahR-F/onahR-R; $0.5 \mu \mathrm{M}$ ), $1 \times$ PCR buffer (Gibco-BRL), dNTP $(50 \mu \mathrm{M}), \mathrm{MgCl}_{2}(1.5 \mathrm{mM})$ and $1 \mathrm{U}$ Taq DNA polymerase (Gibco-BRL). A cycling regime of $94{ }^{\circ} \mathrm{C}$ for $5 \mathrm{~min}$ (1 cycle), $94^{\circ} \mathrm{C}$ for $30 \mathrm{~s}, 43^{\circ} \mathrm{C}$ for $1 \mathrm{~min}, 72^{\circ} \mathrm{C}$ for $1 \mathrm{~min}(30$ cycles) and $72{ }^{\circ} \mathrm{C}$ for $5 \mathrm{~min}$ ( 1 cycle) was employed (PTC-200 thermocycler; MJ Research).

Cloning and sequencing of nahR homologues. The nabR-like genes were amplified with onahR-F and onahR-R primers. The intergenic regions between nabG-like and nabR-like genes were amplified using the degenerate primer set (pro$\mathrm{F}$ /pro-R). Amplified PCR fragments were cloned into pCR2.1TOPO, a ligation-ready vector containing kanamycin and ampicillin resistance genes, and M13 primer sites for sequencing (TOPO TA cloning kit; Invitrogen). Characterization of the cloned inserts was checked by both PCR and enzyme digestion with EcoRI. The constructed plasmids were introduced into E. coli INV- $\alpha \mathrm{F}^{\prime}$ competent cells (One Shot; Invitrogen). In an attempt to optimize clone diversity, E. coli INV- $\alpha \mathrm{F}^{\prime}$ was incubated for only $45 \mathrm{~min}$ at $37^{\circ} \mathrm{C}$ after transformation. Both directions of nahR-like genes were sequenced using M13 reverse and M13 forward primers and all sequencings were completed on an ABI model 377 instrument at the Biological Resource Center, Cornell University, NY. The DNA sequences were aligned by using the MEGALIGN program and all sequence comparisons were computed as percentage identity using CLUSTAL (DNASTAR).

\section{RESULTS AND DISCUSSION}

\section{Identification of an nahR homologue in $P$. putida NCIB 9816-4 and in micro-organisms native to a coal-tar-contaminated site: PCR assay using strains with and without a catabolic plasmid}

The entire pDTG1 plasmid has been sequenced (G. Zylstra, unpublished data). The nabR-like gene (NCIB$n a b R)$ and the nabG-nabR intergenic region of pDTG1 plasmid in P. putida NCIB 9816-4 (Fig. 1a) were identified by preparing an alignment with two other known nabR genes [from the NAH7 plasmid in $P$. putida G7 and from the chromosomally encoded nahR $(S)$ from $P$. stutzeri AN10 (Bosch et al., 1999, 2000)]. When NCIB-nabR was compared to nabR homologues from P. putida G7, P. stutzeri AN10 and Ralstonia sp. strain U2 (Fuenmayor et al., 1998), their amino acid and DNA identities were 90.4/89.5\%, $83 \cdot 7 / 76 \cdot 7 \%$ and $60 \cdot 5 / 60 \cdot 2 \%$, respectively.

The degenerate primers designed from these nabR sequences successfully amplified the entire nabR-like genes (921 bp; using primers onahR-F and onahR-R) and internal fragments (315 bp; using onahR-F and inahR-R) from five wild-type strains, $\mathrm{Cg} 1, \mathrm{Cg} 2, \mathrm{Cg} 5$, Cg7, Cg9, (Fig. 2, lanes 9, 10; 13, 14; 17, 18; 21, 22; and 25, 26; respectively) from our coal tar waste study site in Glens Falls, NY (Herrick, 1995; Herrick et al., 1997; Hohnstock et al., 2000). P. putida NCIB 9816-4 and P. putida G7 (isolated originally from soil from Bangor, Wales and Berkeley, CA, respectively) were used as positive controls (Fig. 2, lanes 1, 2 and 5, 6). P. putida F1 (toluene-degrading bacterium), E. coli $\mathrm{DH} 5 \alpha$, E. coli JM109, plasmid pVIK112 and water were successfully used as negative controls (data not shown). The amplicon with onahR-F/inahR-R and onahR- (a)

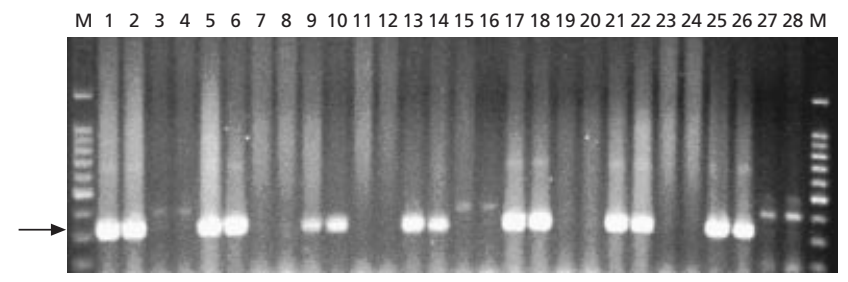

(b)

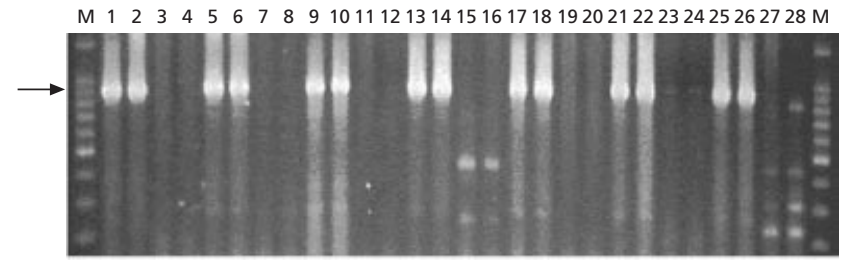

Fig. 2. Agarose (2\%) gel electrophoresis of $P C R$ products from 14 bacteria amplified with two different PCR primer pairs. Duplicate PCR amplifications for each strain were performed to verify reproducibility. Plasmid-cured strains (CR) were used as negative controls. Lanes: 1, 2, P. putida NCIB 9816-4; 3, 4, P. putida NCIB 9816-4CR; 5, 6, P. putida G7; 7, 8, $P$. putida G7CR; 9, 10, P. putida Cg1; 11, 12, P. putida Cg1CR; 13, 14, $P$. fluorescens $\mathrm{Cg} 2 ; 15,16, P$. fluorescens $\mathrm{Cg} 2 \mathrm{CR} ; 17,18$, P. fluorescens Cg5; 19, 20, P. fluorescens Cg5CR; 21, 22, Pseudomonas strain Cg7; 23, 24, Pseudomonas strain Cg7CR; 25, 26, P. fluorescens Cg9; 27, 28, P. fluorescens Cg9CR; M, 100 bp DNA ladder (Promega). (a) Primer pair onahR-F/inahR-R. The amplicon (315 bp) is indicated by an arrow. (b) Primer pair onahR-F/onahR-R. The amplicon (921 bp) is indicated by an arrow.

$\mathrm{F} /$ onahR-R was not found in any plasmid-cured strain derived from the type bacteria ( $P$. putida G7 and NCIB 9816-4) or fived cured site isolates (Fig. 2, lanes 3, 4; 7, $8 ; 11,12 ; 15,16 ; 19,20 ; 23,24 ; 27,28$; sporadic traces of non-specific amplicons were considered insignificant). This shows that the nabR-like gene is present only on the naphthalene-catabolic plasmid in the micro-organisms examined. The amplicons were also found in two additional naphthalene-degrading strains, $P$. fluorescens $\mathrm{N} 1$ and $\mathrm{Nd} 9$ (isolated originally from soil from Richland, WA and Glen Falls, NY, respectively, data not shown). It is worth noting that Silva et al. (1995) failed to amplify an nabR-like sequence by PCR in $P$. fluorescens $\mathrm{Nd} 9$; this undoubtedly reflected the design characteristics of the primers used. These patterns in PCR amplification of nabR suggest that it is highly conserved in pure cultures of naphthalene-utilizing bacteria despite the fact that some naphthalenedegrading strains were isolated from geographically diverse locations.

\section{Genetic and phenotypic characterization of the targeted NCIB-nahR gene}

To verify the putative role of NCIB-nahR in pDTG1, this regulatory gene was disrupted. Campbell-type, single-crossover homologous recombination, using the suicide plasmid pWJ100 (containing an internal nabR- 
(a)

PpNCIB9816-4
PpCg1
PfCg5
PfCg2
PstrainCg7
PpG7
P.stutzerian10

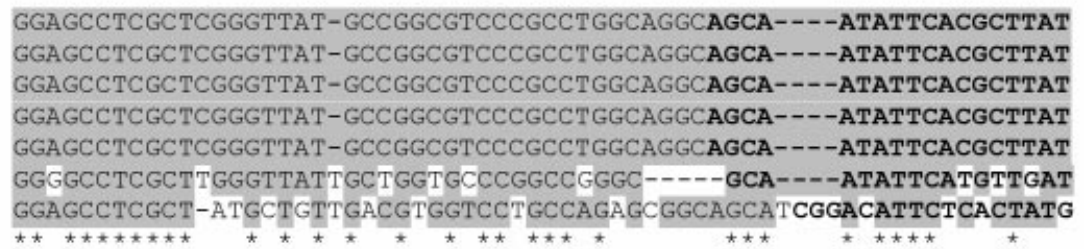

PpNCIB9816-4

$\mathrm{PpCg} 1$

PfCg5

$\mathrm{PfCg} 2$

PstrainCg7

PpG7

P.stutzeriAn10

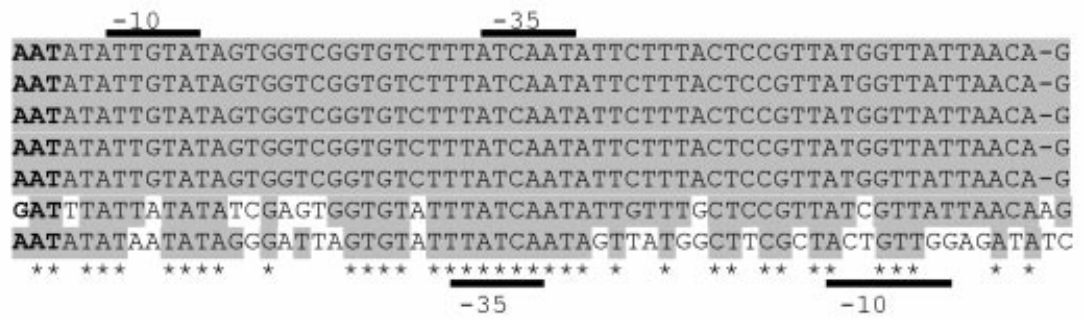

PpNCIB9816-4
PpCg1
PfCg5
PfCg 2
PstrainCg7
PpG7
P.stutzerian10

TCAACTGTAAAACCATCATGAGTACCAGCATG

TCAACTGTAAAACCATCATGAGTACCAGCATG

TCAACTGTAAAACCATCATGAGTACCAGCATG

TCAACTGTAAAACCATCATGAGTACCAGCATG

TCAACTGTAAAACCATCATGAGTACCAGCATG

TCATCAATAAAGCCATCACGAGTAC-AGCATG

P.stutzerian10 CCAATAATAAAGTCATGACAGGTATTGC-ATG

(b)

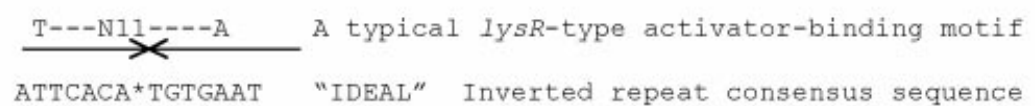

NGCAATATTCACGCTNNTGAT
TCGGACATTCTCACTATGAAT
GGACATTATCATATTAGTGAT
CGCAATATTCATGTIGATGAT
CGCAGTATTCACGCTGGTGAT
AGCAATATCACGCTIATAAT
ATGAGTATTCACATTGGTGAT
AGCAATATTCACGCTIATAAT
ACCATTATICATGCIGGTGAT

Imperfect Inverted repeat consensus sequence

PnahG site in $P$. stutzeri AN10

PnahAa site in P. stutzeri AN10

PrahG site in $P$. putida G7

PnahAa site in $P$. putida G7

PnahG site in $P$. putida NCIB 9816-4

PnahAa site in $P$. putida NCIB 9816-4

PnahG site in PpCg1, PfCg2, PfCg5 PstrainCg7

PnagAa site in Ralstonia sp. strain 02

Schell (1986); Schell \& Wender (1986)

Schell (1986); Schell \& Wender (1986) This study

Simon et al. (1993)

This study

Zhou et al. (2001)

Fig. 3. Comparison of promoter and NahR binding regions. (a) The alignment of nahG promoter regions in $P$. putida NCIB 9816-4, P. putida G7, P. stutzeri AN10 and micro-organisms native to the coal-tar-contaminated site (strains Cg1, $\mathrm{Cg}$ 2, Cg5, Cg7, Cg9). The putative $-10,-35$ regions of nahG and nahR promoters, based on the genetic system of the $\mathrm{NAH7}$ plasmid, are indicated and putative NahR-binding sites for the nahG promoter are in bold type. Pf, $P$. fluorescens; Pp, P. putida; Pstrain, Pseudomonas strain. (b) Consensus binding motifs, based on NahR-binding sequences in $P$. putida G7.

like region), inactivated NCIB-nahR in pDTG1 (Fig. 1b). The sought transconjugant genotype was checked by using the onahR-F/mcs-R primer pair. The expected $372 \mathrm{bp}$ PCR product was obtained only in transconjugant strain RK1, while no product was obtained in either the wild-type strain or E. coli S17-1 $\lambda$ pir(pWJ100). The wild-type and mutant cells were grown overnight on MSB-G liquid medium; from this $10^{9}$ cells were inoculated into fresh MSB-N liquid medium containing various concentrations of suspended naphthalene crystals or $2.5 \mathrm{mM}$ salicylate. The resultant mutant construct, strain RK1, failed to grow in naphthalenecontaining media during a 30 hour incubation, while its parent recoded an $\mathrm{OD}_{600}$ of 0.9 . This result is consistent with previous reports (Schell \& Wender, 1986; Yen \& Serdar, 1988) and confirmed that the nabR homologue in pDTG1 is required for efficient naphthalene utilization.

\section{Comparison of nahG-nahR intergenic regions and NahR binding motifs in naphthalene-degrading bacterial isolates}

nabR-like genes in strains $\mathrm{Cg} 1, \mathrm{Cg} 2, \mathrm{Cg} 5, \mathrm{Cg} 7, \mathrm{Cg} 9$, Cg11, P. putida strain NCIB 9816-4 as well as N1 and $\mathrm{Hg} 8$ were cloned and sequenced. All deduced proteins exhibited a highly conserved helix-turn-helix motif and a putative enhancer-binding region in the $\mathrm{N}$-terminal 
(a)

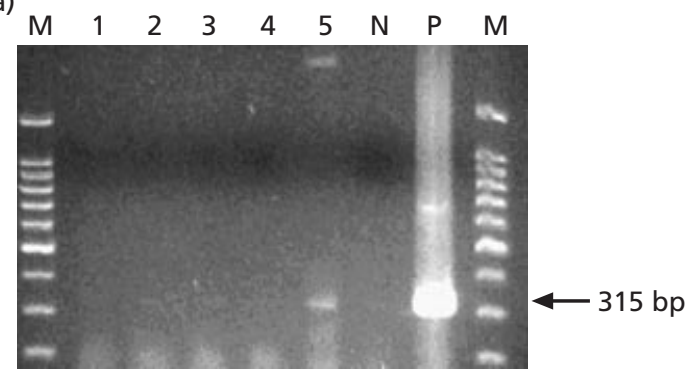

(b)

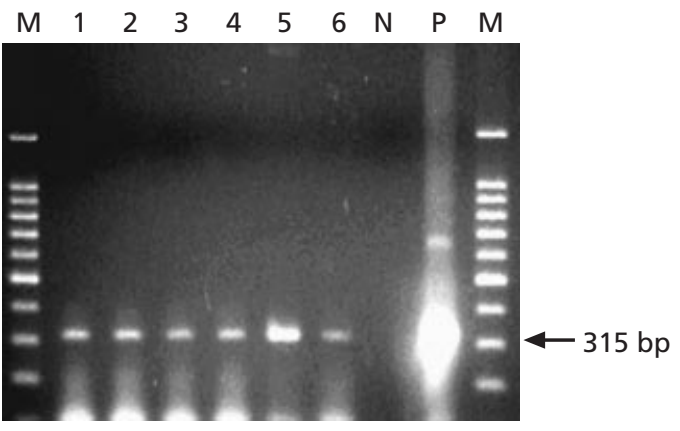

(c)

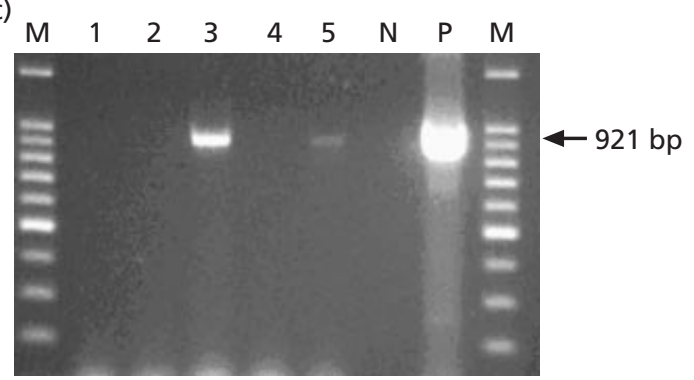

Fig. 4. $P C R$ amplification of nahR-like sequences in sedimentextracted DNA. The following sediment sample sources were used: contaminated aquifer (lane 1), uncontaminated aquifer (lane 2), contaminated source (lane 3), clean sediment (lane 4) and seep sediment (lane 5). On-site frozen seep sediment (lane 6) appears only in (b). Lanes: $N$, negative control (water); $P$, positive control ( $P$. putida NCIB 9816-4); M, 100 bp DNA ladder (Promega). (a) Unenriched sediment DNA was directly extracted and PCR amplification of the $315 \mathrm{bp}$ fragment by the onahRF/inahR-R primer pair is indicated by an arrow. (b) Sediment DNA was extracted after 14 days incubation with naphthalene and distilled water at room temperature $\left(22^{\circ} \mathrm{C}\right)$. The arrow indicates the expected PCR amplicon. (c) Sediment DNA was extracted after 2 days incubation with MSB medium plus naphthalene at $30^{\circ} \mathrm{C}$; the $921 \mathrm{bp}$ fragment amplified with onhaR-F/onahR-R is indicated by an arrow.

domain. nahG from pDTG1 (NCIB-nahG) was identified via a sequence homology search with known nabG genes from $P$. putida G7 and P. stutzeri AN10. When amino acid and nucleotide sequences were compared, NCIB-nabG had 92 and $92.4 \%$ identities, respectively, with nahG from $P$. putida G7. Corresponding identities between NCIB-nabG and nabG from P. stutzeri AN10 were 78.7 and $81.3 \%$.

The $n a b G$ promoter-like region from four site-derived strains was cloned and sequenced. Alignment of nabG gene promoter-like regions from $P$. putida G7, P. stutzeri
AN10, P. putida NCIB 9816-4, Cg1, Cg2, Cg5 and Cg 7 revealed $50 \cdot 4-100 \%$ identity (Fig. 3a). Surprisingly, amplified intergenic regions from naphthalene-degrading micro-organisms native to our study site were $100 \%$ identical to that of the pDTG1 plasmid, while the nabR coding regions were not. Conservation in the intergenic region may possibly be explained by recent acquisition of an nahG-nahR cassette. A high degree of identity was observed around the putative -35 box, and the putative -10 box also showed little variation (Fig. 3a). The $n a h G$ and nahA promoter regions from naphthalenedegrading bacteria revealed the consensus $\mathrm{NahR}$ binding sites $\left(5^{\prime}\right.$-ATTCACGCTN ${ }_{2}$ TGAT- $\left.3^{\prime}\right)$ that consists of imperfect inverted repeat sequences (Fig. 3b). The upstream sequences of $n a g A a$ also showed putative NahR binding sites (Zhou et al., 2001). These data support previously published RFLP analyses suggesting that naphthalene-catabolic plasmids in isolates from our coal-tar-contaminated site are closely related to the pDTG1 plasmid in P. putida NCIB 9816-4, despite the fact that $P$. putida NCIB 9816-4 was originally isolated in Wales (Stuart-Keil et al., 1998). The highly conserved sequences of $n a b R$ and its $5^{\prime}$ flanking region suggest that this regulatory gene and promoter region may behave as an intact gene cassette on pDTG1-like plasmids and may have evolved independently from the structural genes for the catabolic enzymes. It is also possible that the regulator, $n a h R$, and the entire lower operon could together be a conserved cassette.

\section{PCR detection of nahR from the sediment-derived microbial community DNA}

The above results gave us confidence that our PCR primers were suitable for amplifying nabR in many micro-organisms and that NCIB-nahR had the expected regulatory role in pDTG1-like plasmids, previously shown to be present in sediments (Stuart-Keil et al., 1998) and waters (Hohnstock et al., 2000) in the study site. DNA extracted from six site-derived sediment samples was used in a survey of community-derived nabR-like genes (Fig. 4). The extracted DNA samples were diluted $1: 10$ in distilled water to reduce the influence of humic acids and related interferences to the PCR reaction. PCR amplification used onahR-F/inahR$\mathrm{F}$ and onahR-F/onahR-R primer sets and a low stringency annealing temperature of $43^{\circ} \mathrm{C}$. DNA from the on-site frozen seep sediment was assayed identically to the other five samples, but only the positive result is shown (Fig. 4b; lane 6). The expected 315 bp fragment amplified by primers onahR-F/inahR-R was successfully obtained from one of the six sediment-derived DNA extracts, the naphthalene-rich seep sample stored at $4{ }^{\circ} \mathrm{C}$ (Fig. $4 a$; lane 5 ). Amplification of the entire nabR-like gene with the onahR-F/onahR-R primer set failed when using DNA extracts from all six sediment samples (data not shown). Negative results from amplification attempts are difficult to interpret because they can reflect a variety of factors, including lack of target genes, death of target cells during storage, sheared DNA and/or presence of materials that inhibit the PCR. 


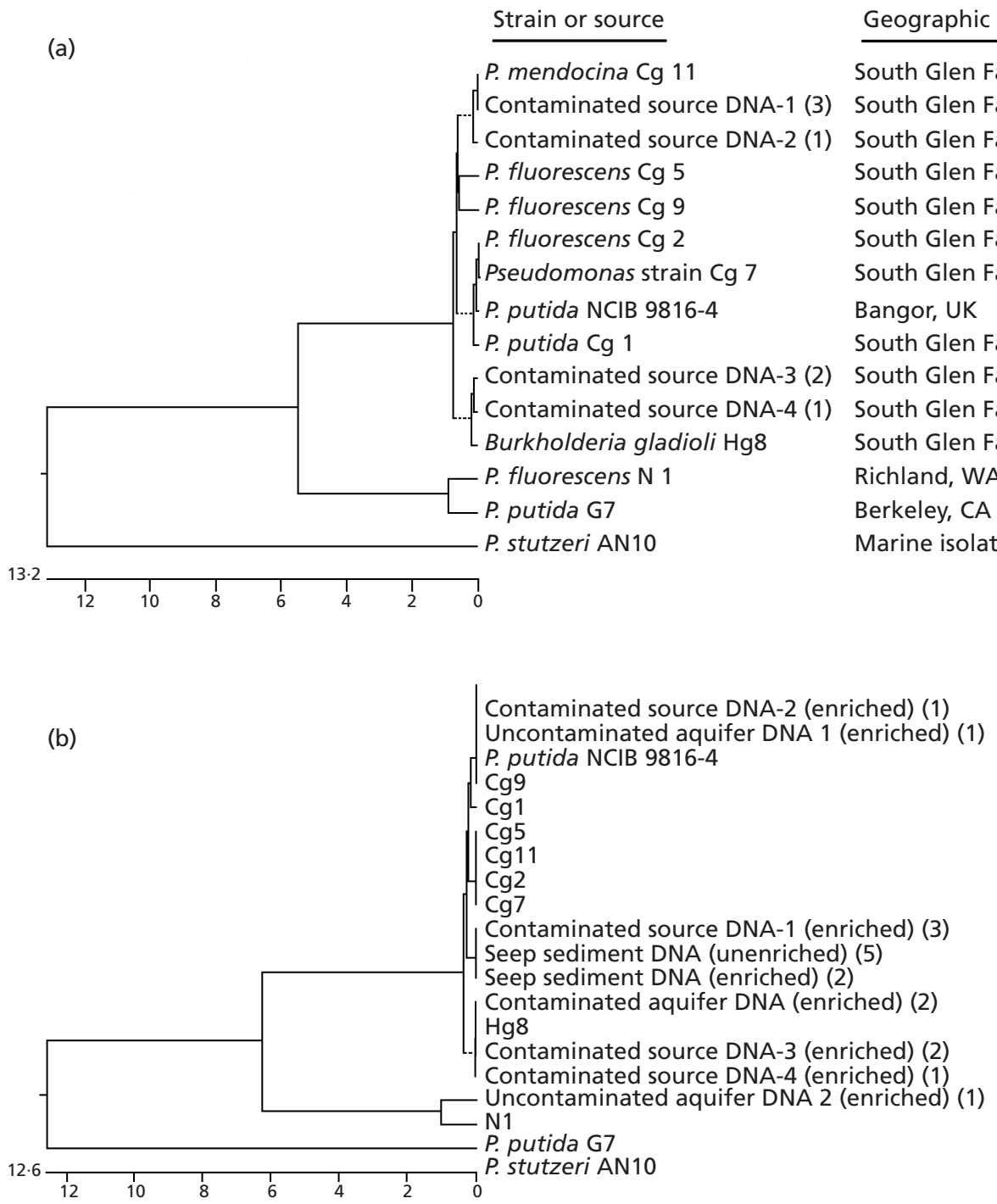

Fig. 5. Comparison of full and partial nahR-like sequences from cultured and uncultured micro-organisms. The number of sediment DNA clones with identical sequences is shown in parentheses after each entry. Dendrograms were prepared using CLUSTAL with a PAM250 residue weight table. Geographic origins of sequences are shown. (a) Dendrogram of nahR homologues based on the entire nahR DNA sequences from 11 naphthalene-degrading bacteria and 7 clones from sediment-extracted DNA (contaminated source; lane 3 in Fig. 4c). (b) Dendrogram of N-terminal 297 bp nahR sequences from 11 naphthalene-degrading bacteria and 18 clones from sediment-extracted DNA: 5 clones from unenriched seep sediment (Fig. 4a; lane 5); 2 clones each from enriched contaminated aquifer (Fig. 4b; lane 1), enriched uncontaminated aquifer (Fig. 4b; lane 2) and enriched seep sediment (Fig. 4b; lane 5); and 7 clones from enriched contaminated source (Fig. 4c; lane 3).

Because naphthalene is a volatile compound, it may have been lost during sediment storage, thus decreasing selective pressure for naphthalene-degrading populations. To investigate the response of nabR-containing sediment micro-organisms to selective pressure, we enriched our sediment samples three ways. When naphthalene and water were added to sediments and incubated at room temperature for 14 days, the $315 \mathrm{bp}$ amplicon from primers onahR-F/inahR-R was produced from all six samples (Fig. 4b; lanes 1-6). The $315 \mathrm{bp}$ fragment was also found in naphthalene plus nitrogen/phosphorous-enriched sediment samples (data not shown). Post-incubation appearance of the amplicon probably occurred after growth of initially low numbers of naphthalene-degrading bacteria during incubation. However, the entire nabR gene could not be amplified from any sediment sample under the above two enrichment conditions using the onahR-F/onahR-R primer pair (data not shown). When sediment samples were incubated with a complete nutritional supplement (MSB-N medium) containing naphthalene for 2 days at $30{ }^{\circ} \mathrm{C}$, the 315 bp nabR fragments were detected in all sediment samples (data not shown). In addition, the entire $921 \mathrm{bp}$ nabR gene product became amplifiable only in samples from the source and seep areas of the study site (Fig. 4c; lanes 3 and 5). 


\section{Sequencing and alignment of nahR-like genes from sediment-extracted DNA}

The amplified PCR products of the entire nabR gene from the enriched contaminated source DNA (Fig. $4 \mathrm{c}$; lane 3) were cloned. Seven randomly chosen clones were sequenced and compared to the corresponding sequences from site-derived and reference pure cultures. Three main clades were found (Fig. 5a). All four distinctive sediment DNA clone sequences (designated 'contaminated source DNA-1 to -4') fell into the uppermost clade of Fig. 5(a), along with sequences from seven site-derived pure cultures and the type strain, $P$. putida NCIB 9816-4. In two instances (contaminated source DNA-1 and -3), more than one DNA clone had identical sequences (Fig. 5a). Scrutiny of nabR homologues revealed that the sequences from strain N1 and $P$. putida G7 cluster together (Fig. 5a). Furthermore, the chromosomally encoded $n a h R(S)$ is quite different from any other of the plasmid-encoded NahR homologues (Fig. 5a). The sequence of nahR from strain $\mathrm{Hg} 8$ showed that $2 \mathrm{nt}$ are missing in the $\mathrm{C}$-terminal region near the stop codon. However, like the terminal nucleotide sequences of $n a b R$ in some $\mathrm{Cg}$ strains, $\mathrm{Hg} 8$ featured two out-of-frame 5'-CTGATTGA-3' stop codons. This may compensate for the two missing nucleotides. Thus, nabR of strain $\mathrm{Hg} 8$ has 298 instead of 300 aa but retains a high level of identity to other nabR genes. The nabRlike sequences from cultured and uncultured microorganisms featured a nucleotide identity range of $74 \cdot 6-100 \%$ and an amino acid identity range of $81 \cdot 4$ $100 \%$. Thus, although subtle sequence variations were found in the nabR-like sequences displayed in Fig. 5(a), the dendrogram generally confirms that nabR-like genes are highly conserved, regardless of their varied geographic origins or their cultivated versus non-cultivated hosts (Fig. 5a).

Because microbial genetic diversity is likely to be inversely proportional to the degree of selective enrichment (Beaulieu et al., 2000; Dunbar et al., 1997; Ramirez-Saad et al., 2000), we hypothesized that the most likely reservoir of divergent nahR genes would be PCR amplicons from unenriched seep sediment (Fig. $4 \mathrm{a}$; lane 5). Therefore, we cloned, sequenced and compared the 315 bp nahR fragment from this communityderived DNA to the corresponding fragments in our collection of pure cultures, in the sediment DNA clones shown in Fig. 5(a) and in DNA derived from three $315 \mathrm{bp}$ bands from enrichments shown in Fig. 4(b). A dendrogram is shown in Fig. 5(b) that compares the 315 bp nahR-like fragment from 11 bacteria, five clones from the unenriched seep sediment DNA, six clones from enriched sediments (two each from lanes 1, 2, 5 in Fig. 4b) and seven clones from the MSB mediumenriched sediment (Fig. 4c; lane 3). As expected, the 3clade structure of Fig. 5(a) is present in Fig. 5(b). Five clones from unenriched seep sediment were randomly chosen for sequencing; remarkably, these were identical. The amplified fragment from the unenriched DNA from the seep sediment features an amino acid identity of $87 \cdot 9 \%$ and a nucleotide identity of $87.2 \%$ with $n a b R$ in
P. putida G7; corresponding values for $P$. putida NCIB 9816-4 are 99.7 and $99.0 \%$, respectively. Surprisingly, the sequences from the unenriched and enriched seep sediment samples were identical (Fig. 5b). The $315 \mathrm{bp}$ fragments from enriched contaminated aquifer, uncontaminated aquifer, contamination source and seep sediment samples had an identity value $>99.3 \%$ with NCIB-nabR. Thus, all community-derived nabR sequences were quite similar (Fig. 5b). These results indicate that $n a b R$ genes are highly conserved both in uncultured and cultured naphthalene-degrading bacteria - although we cannot exclude the possibility of selective detection 'bias' with our two degenerate primer pair sets. A clear element of tautology (circular logic) is unavoidable in the approach taken in the present study: when PCR primers are the main tools for seeking genetic diversity in community DNA, discovering conserved sequences should not be a surprise. Although we took steps to reduce primer bias (degeneracy and low stringency), we fully acknowledge that there might be NahR-like transcriptional regulators that have quite different sequences in naphthalenedegrading micro-organisms, but these would be undetectable with our nabR-specific primers pairs.

\section{Speculation about selective pressure on nahR and operon evolution}

Interestingly, the upstream region of $n a b G$ gene in pDTG1 has tnpA (transposase)-like sequences (Fig. 1a). The truncated $414 \mathrm{bp}$ nucleotide sequence of the $\operatorname{tn} p A$ like gene from pDTG1 has $100 \%$ identity with tnpA of Pseudomonas strain CA10 (a carbazole-degrading bacterium) and $87 \%$ DNA identity with $t n p A 3$ of $P$. strain O1G3 (an alkylbenzene-catabolic strain). This observation suggests that regulatory genes might in the past have been transferred in the form of a composite transposon. Bosch et al. (2000) have shown that nabW (salicylate hydroxylase) in P. stutzeri AN10 is located between $t n p A 2$ and $t n p A 3$ and its position is adjacent to a lower pathway operon where $n a b R(S)$ and an additional copy of nabG (salicylate hydroxylase) reside. It has been suggested (Bosch et al., 1999, 2000), based on gene organization of the naphthalene-catabolic operon in $P$. stutzeri AN10, that the first step in assembling a naphthalene-degradation pathway may have been acquisition of a catechol meta-cleavage pathway (conferring catechol mineralization). The next theoretical step in operon assembly may be the acquisition of $n a b G$ (to form the lower pathway) and then acquisition of the upper pathway operon. Incorporation of the nabR regulatory gene may have been the last step.

Current paradigms suggest that biodegradative operons evolved from constitutive expression to substrate-dependent control by acquiring genetic regulatory components (Cases \& de Lorenzo, 2001; de Lorenzo \& Perez-Martin, 1996; van der Meer et al., 1992; Williams \& Sayers, 1994). This theory is supported partly by the fact that one type of regulatory protein can activate many types of operons. A major conclusion of the 
present study is that nahR shows remarkably little sequence variation. As acknowledged above, this apparent conservation may reflect the PCR-based methodology. But if we accept the results as reflecting the true disposition of nabR in soil microbial communities, we have license to speculate about selective pressures that act on regulatory versus structural genes in catabolic operons. It is obvious that the various forms of aromatic substrates (e.g. toluene, biphenyl, naphthalene, phenol) require substantial evolutionary malleability in structural catabolic genes. Drift at the sequence level is translated into gradual refinement of enzyme recognition sites that accommodate needs to bind, destabilize and catalyse electron transfer and oxygenase attack of aromatic rings (van der Meer et al., 1992; Williams \& Sayers, 1994). It is possible that the DNA sequences encoding the regulatory components (nahR-type genes) of such catabolic operons have been optimized during multiple 'recruitment' events. Progress towards explaining high conservancy of nabR, recruitment of nabR and other issues in operon evolution may occur through continued comparative genetic analysis of catabolic operons.

\section{ACKNOWLEDGEMENTS}

This research was supported by NSF grants MCB-0084175 (to E.L.M.) and MCB-0078465 (to G. J.Z.). We would like to thank Dr Stephen C. Winans for providing pVIK112. P. Padmanabhan was supported by an Overseas Associateship from the Department of BioTechnology, Ministry of Science and Technology, India.

\section{REFERENCES}

Ausubel, F. M., Brent, R., Kingston, R. E., Moore, D. D., Seidman, J. G., Smith, J. A. \& Struhl, K. (1994). Current Protocols in Molecular Biology. New York: Wiley.

Beaulieu, M., Becaert, V., Deschenes, L. \& Villemur, R. (2000). Evolution of bacterial diversity during enrichment of PCPdegrading activated soils. Microb Ecol 40, 345-355.

Bosch, R., Garcia-Valdes, E. \& Moore, E. R. (1999). Genetic characterization and evolutionary implications of a chromosomally encoded naphthalene-degradation upper pathway from Pseudomonas stutzeri AN10. Gene 236, 149-157.

Bosch, R., Garcia-Valdes, E. \& Moore, E. R. (2000). Complete nucleotide sequence and evolutionary significance of a chromosomally encoded naphthalene-degradation lower pathway from Pseudomonas stutzeri AN10. Gene 245, 65-74.

Cane, P. A. \& Williams, P. A. (1986). A restriction map of the catabolic plasmid pWW60-1 and location of some of its catabolic genes. J Gen Microbiol 132, 2919-2929.

Cases, I. \& de Lorenzo, V. (2001). The black cat/white cat principle of signal integration in bacterial promoter. EMBO J 20, $1-11$.

Cebolla, A., Sousa, C. \& de Lorenzo, V. (1997). Effector specificity mutants of the transcriptional activator NahR of naphthalene degrading Pseudomonas define protein sites involved in binding of aromatic inducers. J Biol Chem 272, 3986-3992.

Connors, M. A. \& Barnsley, E. A. (1980). Metabolism of naphthalene by pseudomonads: salicylaldehyde as the first possible inducer in the metabolic pathway. J Bacteriol 141, 1052-1054. de Lorenzo, V. \& Perez-Martin, J. (1996). Regulatory noise in prokaryotic promoters: how bacteria learn to respond to novel environmental signals. Mol Microbiol 19, 1177-1184.

Dunbar, J., White, S. \& Forney, L. (1997). Genetic diversity through the looking glass: effect of enrichment bias. Appl Environ Microbiol 63, 1326-1331.

Eaton, R. W. (1994). Organization and evolution of naphthalene catabolic pathways: sequence of the DNA encoding 2-hydroxychromene-2-carboxylate isomerase and trans-o-hydroxybenzylidenepyruvate hydratase-aldolase from the NAH7 plasmid. $J$ Bacteriol 176, 7757-7762.

Fuenmayor, S. L., Wild, M., Boyes, A. L. \& Williams, P. A. (1998). A gene cluster encoding steps in conversion of naphthalene to gentisate in Pseudomonas sp. strain U2. J Bacteriol 180, 25222530.

Goyal, A. K. \& Zylstra, G. J. (1996). Molecular cloning of novel genes for polycyclic aromatic hydrocarbon degradation from Comamonas testosteroni GZ39. Appl Environ Microbiol 62, 230-236.

Goyal, A. K. \& Zylstra, G. J. (1997). Genetics of naphthalene and phenanthrene degradation by Comamonas testosteroni. J Ind Microbiol Biotechnol 19, 401-407.

Herrick, J. B. (1995). Detection, divergence, and phylogeny of a naphthalene dioxygenase and naphthalene degrading bacteria native to a coal tar-contaminated site. $\mathrm{PhD}$ thesis. Cornell University, Ithaca, NY, USA.

Herrick, J. B., Stuart-Keil, K. G., Ghiorse, W. C. \& Madsen, E. L. (1997). Natural horizontal transfer of a naphthalene dioxygenase gene between bacteria native to a coal tar-contaminated field site. Appl Environ Microbiol 63, 2330-2337.

Hohnstock, A. M., Stuart-Keil, K. G., Kull, E. E. \& Madsen, E. L. (2000). Naphthalene and donor cell density influence field conjugation of naphthalene catabolism plasmids. Appl Environ Microbiol 66, 3088-3092.

Huang, J. Z. \& Schell, M. A. (1991). In vivo interactions of the $\mathrm{NahR}$ transcriptional activator with its target sequences. Inducermediated changes resulting in transcription activation. $\mathrm{J} \mathrm{Biol}$ Chem 266, 10830-10838.

Kalogeraki, V. S. \& Winans, S. C. (1997). Suicide plasmids containing promoterless reporter genes can simultaneously disrupt and create fusions to target genes of diverse bacteria. Gene 188, 69-75.

Kurkela, S., Lehvaslaiho, H., Palva, E. T. \& Teeri, T. H. (1988). Cloning, nucleotide sequence and characterization of genes encoding naphthalene dioxygenase of Pseudomonas putida strain NCIB 9816. Gene 73, 355-362.

Larkin, M. J., Allen, C. C., Kulakov, L. A. \& Lipscomb, D. A. (1999). Purification and characterization of a novel naphthalene dioxygenase from Rhodococcus sp. strain NCIMB12038. J Bacteriol $181,6200-6204$.

Laurie, A. D. \& Lloyd-Jones, G. (1999). The $p h n$ genes of Burkholderia sp. strain RP007 constitute a divergent gene cluster for polycyclic aromatic hydrocarbon catabolism. J Bacteriol 181, 531-540.

Laurie, A. D. \& Lloyd-Jones, G. (2000). Quantification of $p h n A c$ and $n a b A c$ in contaminated New Zealand soils by competitive PCR. Appl Environ Microbiol 66, 1814-1817.

Madsen, E. L., Sinclair, J. L. \& Ghiorse, W. C. (1991). In situ biodegradation: microbiological patterns in a contaminated aquifer. Science 252, 830-833.

Miller, J. H. (1972). Experiments in Molecular Genetics. Cold Spring Harbor, NY: Cold Spring Harbor Laboratory. 
Pieper, D. H. \& Reineke, W. (2000). Engineering bacteria for bioremediation. Curr Opin Biotechnol 11, 262-270.

Ramirez-Saad, H. C., Sessitsch, A., de Vos, W. \& Akkermans, A. D. (2000). Bacterial community change and enrichment of Burkholderia-like bacteria induced by chlorinated benzoates in a peatforest soil-microcosm. Syst Appl Microbiol 23, 591-598.

Saito, A., Iwabuchi, T. \& Harayama, S. (2000). A novel phenanthrene dioxygenase from Nocardioides sp. Strain KP7: expression in Escherichia coli. J Bacteriol 182, 2134-2141.

Sambrook, J., Fritsch, E. F. \& Maniatis, T. (1989). Molecular Cloning: a Laboratory Manual, 2nd edn. Cold Spring Harbor, NY: Cold Spring Harbor Laboratory.

Schell, M. A. (1985). Transcriptional control of the nah and sal hydrocarbon-degradation operons by the nabR gene product. Gene 36, 301-309.

Schell, M. A. (1986). Homology between nucleotide sequences of promoter regions of $n a h$ and sal operons of NAH7 plasmid of Pseudomonas putida. Proc Natl Acad Sci U S A 83, 369-373.

Schell, M. A. (1993). Molecular biology of the LysR family of transcriptional regulators. Annu Rev Microbiol 47, 597-626.

Schell, M. A. \& Poser, E. F. (1989). Demonstration, characterization, and mutational analysis of NahR protein binding to $n a b$ and sal promoters. J Bacteriol 171, 837-846.

Schell, M. A. \& Wender, P. E. (1986). Identification of the nahR gene product and nucleotide sequences required for its activation of the sal operon. J Bacteriol 166, 9-14.

Schell, M. A., Brown, P. H. \& Raju, S. (1990). Use of saturation mutagenesis to localize probable functional domains in the NahR protein, a LysR-type transcription activator. J Biol Chem 265, 3844-3850.

Serdar, C. M. \& Gibson, D. T. (1989). Studies of nucleotide sequence homology between naphthalene-utilizing strains of bacteria. Biochem Biophys Res Commun 164, 772-779.

Shuttleworth, K. L. \& Cerniglia, C. E. (1995). Environmental aspects of PAH biodegradation. Appl Biochem Biotechnol 54, 291-302.

Silva, M. C., More, M. I. \& Batt, C. A. (1995). Development of a molecular detection method for naphthalene degrading pseudomonads. FEMS Microbiol Lett 18, 225-235.

Simon, M. J., Osslund, T. D., Saunders, R. \& 7 other authors (1993). Sequences of genes encoding naphthalene dioxygenase in Pseudomonas putida strains G7 and NCIB 9816-4. Gene 127, 31-37.
Simon, R., Priefer, U. \& Pühler, A. (1983). A broad host-range mobilization system for in vivo genetic engineering: transposon mutagenesis in gram-negative bacteria. Bio/Technology 1, 784791.

Stanier, R. Y., Palleroni, N. J. \& Doudorhoff, M. (1966). The aerobic pseudomonads: a taxonomic study. J Gen Microbiol 43, 159-271.

Stuart-Keil, K. G., Hohnstock, A. M., Drees, K. P., Herrick, J. B. \& Madsen, E. L. (1998). Plasmids responsible for horizontal transfer of naphthalene catabolism genes between bacteria at a coal tarcontaminated site are homologous to pDTG1 from Pseudomonas putida NCIB 9816-4. Appl Environ Microbiol 64, 3633-3640.

Sutherland, J. B., Rafii, F., Khan, A. A. \& Cerniglia, C. E. (1995). Mechanisms of polycyclic aromatic hydrocarbon degradation. In Microbial Transformation and Degradation of Toxic Organic Chemicals, pp. 269-306. Edited by L. Y. Young \& C. E. Cerniglia. New York: Wiley.

Timmis, K. N. \& Pieper, D. H. (1999). Bacteria designed for bioremediation. Trends Biotechnol 17, 200-204.

van der Meer, J. R., de Vos, W. M., Harayama, S. \& Zehnder, A. J. B. (1992). Molecular mechanism of genetics adaptation to xenobiotics compounds. Microbiol Rev 56, 677-694.

Williams, P. A. \& Sayers, J. R. (1994). The evolution of pathways for aromatic hydrocarbon oxidation in Pseudomonas. Biodegradation 5, 195-217.

Yen, K. M. \& Gunsalus, I. C. (1982). Plasmid gene organization: naphthalene/salicylate oxidation. Proc Natl Acad Sci US A 79, 874-878.

Yen, K. M. \& Serdar, C. M. (1988). Genetics of naphthalene catabolism in pseudomonads. Crit Rev Microbiol 15, 247-268.

Zhou, N. Y., Fuenmayor, S. L. \& Williams, P. A. (2001). nag genes of Ralstonia (formerly Pseudomonas) sp. strain U2 encoding enzymes for gentisate catabolism. J Bacteriol 183, 700-708.

Zhou, N. Y., Al-Dulayymi, J., Baird, M. S. \& Williams, P. A. (2002). Salicylate 5-hydroxylase from Ralstonia sp. strain U2: a monooxygenase with close relationships to and shared electron transport proteins with naphthalene dioxygenase. J Bacteriol 184, $1547-1555$.

Received 19 December 2001; revised 22 March 2002; accepted 18 April 2002. 